\title{
Copper versus culture
}

\section{Mining could provide a steady stream of income for Afghanistan. But the mere promise of a stable economy does not justify all sacrifices.}

When the United States Geological Service revealed that up to one trillion dollars worth of mineral deposits could be mined from Afghan soils (New York Times; 13 June 2010), the world paid attention. Hopes ran high for a fundamental change in the country's economy - towards one based on anything but opium or Western aid.

But there is a fly in the ointment, at least for one location. The China Metallurgical Group Corporation, who won the rights to mine copper in the Aynak valley south of Kabul, are not the first to show an interest in the place. Buddhist monks entertained a flourishing monastery there between the second and at least the sixth century вС (Science 329, 496-497; 2010). The monks left artefacts, including clay statues and wooden and stone Buddhas, and a monastery complex of archaeological importance. These are now under threat of demolition: their preservation would complicate the mining.

On initial consideration, restricting the mining to preserve the monastery may seem a luxury that Afghanistan cannot afford. The country needs cash. The development of a mining industry and infrastructure could provide a source of income for many. And an alternative revenue stream from tourism to the archaeological site seems rather far off, given the state of the country.

But creating a working economy from the exploitation of natural resources is by no means straightforward: despite enormous riches in raw mineral ores, the Democratic Republic of Congo is neither stable nor affluent. Turning a wealth of raw materials into wealth for the people requires careful strategy and good governance.

The potential benefits of preserving an archaeological site are more subtle. From an Afghan point of view, destruction of the ancient treasures at Aynak could further undermine any sense of pride in the rich cultural heritage of the region that may be developing. And for the world at large, it would mean the irretrievable loss of a central piece in the puzzle of religious evolution in and around Central Asia. But of course, there is no easy way to measure any of this in US dollars.

Perhaps the supply of raw materials, including copper, needs a fresh approach. One way forward would be to limit the use of scarce elements in new products (Nature Geosci. 1, 720-721; 2008). A complementary approach would be to scale up the use of precious metals in waste products such as old computers and mobile phones. According to a United Nations Environmental Programme report published earlier this year, around 30\% of the primary production of copper went into electric and electronic equipment in 2006 - eventually to be dumped (http://go.nature.com/amMbCa).

As the volumes of electronic waste are expected to multiply, systematic and widespread recycling could take some of the pressure off the mining industry - and the price of copper. Preservation of the remains of a monastery that has withstood centuries of turmoil would then, perhaps, seem less extravagant.

\section{Phytoplankton flounder}

\section{The foundation of the marine food web is faltering, according to a century-long data set.}

The global ocean supports a vast array of species, from the humble barnacle to the baleen whale. Anthropogenic climate change could threaten this biodiversity. Rising ocean temperatures have led to the bleaching and collapse of coral reefs. Declines in Southern Ocean sea ice seem to have deprived Antarctic krill - a food source for seals, penguins and whales - of a winter retreat. And it now transpires that ocean energy gains have taken their toll on a slightly less emotive, but no less important, group of organisms.

Phytoplankton - miniature photosynthetic organisms that float in the ocean - form the foundation of the marine food web. Collectively, phytoplankton capture large amounts of energy from the sun and convert it into organic matter, which supports all manner of marine life. A survey of global ocean transparency and chlorophyll measurements - spanning 1899 to the present day - revealed that phytoplankton levels have declined by approximately $1 \%$ per year over the past century (Nature 466, 591-596; 2010). The decrease was greatest in high-latitude and equatorial waters, and in open ocean areas far removed from the coast.

Rising sea surface temperatures may be responsible for the decline, according to an analysis of key climate variables. As the upper ocean warms, surface waters will mix less vigorously with the nutrient-rich deep ocean. This, in turn, could cut off phytoplankton food supplies.

But it's not just phytoplankton nutrient uptake that is influenced by sea surface temperatures. A separate analysis, of more than 11,000 marine organisms, suggests that patterns of diversity are shaped by sea surface temperatures (Nature 466, 1098-1101; 2010). The study is part of the Census of Marine Life, a ten-year initiative designed to document the diversity, distribution and abundance of life in the oceans. The complete census is due to be published in October and could provide a useful baseline for examining the impact of future physical change, and the loss of organisms such as phytoplankton, on marine ecosystems.

Apart from supporting much of marine life, phytoplankton help sequester carbon dioxide from the atmosphere and generate large quantities of oxygen. Thus the decrease in their abundance does not bode well for the planet. However, without a more mechanistic understanding - which cannot be derived from records of ocean clarity and chlorophyll content alone - it is impossible to say whether the phytoplankton decline can or should be extrapolated into the future.

But the findings are a wake-up call. Global ocean phytoplankton levels and physiology need to be monitored closely over the next few decades if unpleasant surprises are to be avoided. Oceancolour satellites offer the best and most informative approach for assessing changes in phytoplankton biomass. Funding for these missions must be secured. 